\title{
INTEGRATED GRAPHICAL ENVIRONMENT FOR SUPPORT NONLINEAR DYNAMIC SOFTWARE FOR THE ANALYSIS OF PLANE FRAMES
}

\author{
Rodrigues, H. ; Romão, X. ${ }^{* *}$; Costa, A. ${ }^{*}$ \& Varum, H. ${ }^{*}$ \\ *Department of Civil Engineering, University of Aveiro, \\ Campus Universitário de Santiago, 3810-193 Aveiro, Portugal \\ *** Department of Civil Engineering, University of Porto, \\ Rua Dr. Roberto Frias, 4200-465 Porto, Portugal \\ E-Mail: hrodrigues@aveiro-norte.ua.pt; xnr@fe.up.pt; acosta@civil.ua.pt; hvarum@civil.ua.pt
}

\begin{abstract}
Nonlinear structural analyses allow reproducing in a more realistic sense the behaviour of structures subjected to several types of complex loading conditions, e.g. earthquakes. However, it is largely recognized that these analyses normally generate a considerable amount of results, being difficult its interpretation. Over the last years considerable progresses have been made in structural nonlinear behaviour modelling, associated to the fast growing development of numerical algorithms for structural analysis and computer capacities. However, a similar growth in the development of graphical results visualization tools has not been witnessed. To face this, a graphical processor called VISUALANL was developed for an existing nonlinear dynamic analysis program for plane frame structures, PORANL.

(Extended paper from the International Symposium CompIMAGE - Coimbra, Portugal, 20-21 October 2006.)
\end{abstract}

Key Words: Visual Interface, Engineering Software, Structural Analysis, Non-linear Models, RC Structures

\section{INTRODUCTION}

The countless programs developed in the last years for the non-linear structural analysis, at academic level, are not used by the engineers, because in many of these programs is verified the lack of graphical interfaces, which creates strong barriers in its use. Traditionally, data input for these programs was made through extensive text files, with a defined and rigid sequence. The results were also presented in long text files, without any or poor graphical visualization. To face this, a graphic tool, VISUALANL, was developed for a non-linear dynamic program for analysis of plane frames, PORANL [1]. In the developed tool, the introduction and modifications of data are made easily in an interactive way, with graphic representation at run-time, through dialogue windows. It should be underlined that, the philosophy followed in the graphical tool does not force a rigid sequence in the data input. For the results interpretation, the program allows an easy visualization through graphic representations. To create the resources needed for preparation, manipulation and visualization of a structural analysis problem, considering material non-linear and dynamic behaviour, it were implemented in the development of this tool countless graphic design concepts, based in the programming language Visual Basic, version 6.0 [3].

In this article is briefly described the structural models involved in the program PORANL, being highlighted the potentialities of the graphic processor developed, at levels of data generation, as well as, results visualization. 


\section{BEHAVIOUR MODELS IMPLEMENTED}

\subsection{Structural behaviour models}

Varum [1] implemented a non-linear analysis model that represents the response of RC frame elements subjected predominantly to bending, based on hysteretic Takeda's model [11], previously developed by Costa [5]. This model considers that the inelastic deformations are concentrated in the vicinity of the element extremities, in which occurs the non-linear behaviour. Each structural frame element is subdivided in three sub-elements (as represented in Fig. 1), namely a central sub-element with elastic-linear behaviour, being linked, at each extremity, a sub-element with non-linear behaviour (plastic hinges).

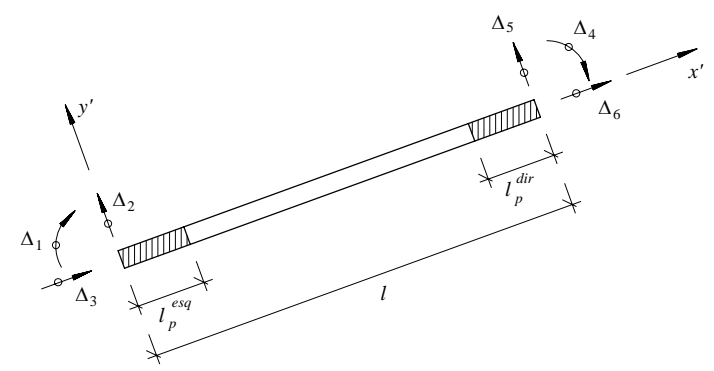

Figure 1: Frame macro-element.

The behaviour of each plastic hinge is represented through the hysteretic model [11]. This model contemplates: i) stiffness degradation; ii) strength degradation; iii) P- $\Delta$ effect; iv) pinching effect; v) slipping; vi) possibility to define different behaviour for positive and negative moments. A detailed description of these models is given in $[1,6,14]$. The behaviour of each plastic hinges is represented by a tri-linear curve, see Fig. 2, for each direction, allowing the analysis of non-symmetrical RC cross-sections. The tri-linear behaviour curve is defined by nine parameters: $K_{0}, K_{1}^{+}, K_{1}^{-}, K_{2}^{+}, K_{2}^{-}, D_{c}^{+}, D c^{-}, D_{y}{ }^{+}$and $D_{y}{ }^{-}$ (Fig. 2). Additionally, three other parameters are considered to characterize: i) stiffness degradation $(\alpha)$; ii) strength degradation $(\gamma)$; and, iii) pinching and slipping effect $(\beta)$.

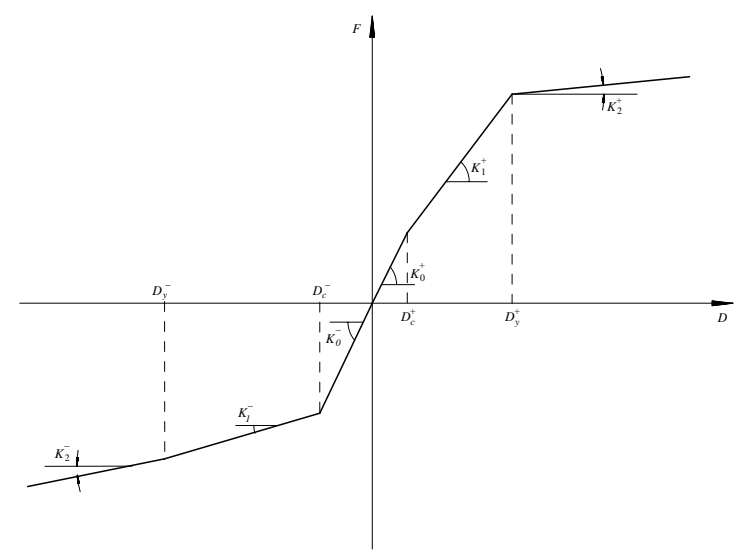

Figure 2: Envelop non-linear moment-curvature behaviour curve.

The non-linear behaviour curves of RC sections can be obtained from a fibre model, as the implemented in the program BIAX, developed by Vaz [6]. The BIAX program was also integrated in the graphic atmosphere of VISUALANL (see Fig. 3). 

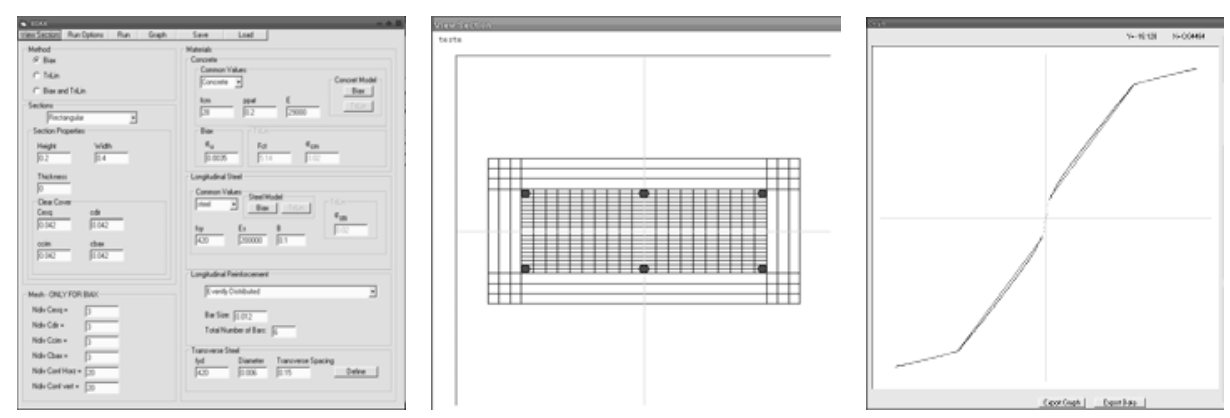

Figure 3: Graphical interface for the fibre model: data generation, section visualization, non-linear behaviour curve.

In this model, elements are discretized, at section level, in slices (in the case of uniaxial bending) or filaments (in the case of biaxial bending), as represented in the Fig. 4. It is considered the uniaxial behaviour at longitudinal axis direction, being neglected the nonlinearities in shear. It is assumed that cross-sections remain plane after deformation. Thus, it is possible to calculate the field of axial extensions in the section, function of the axial extension and curvatures. From the deformation at each fibre, it is obtained the stress from the stress-strain relation defined for each material.

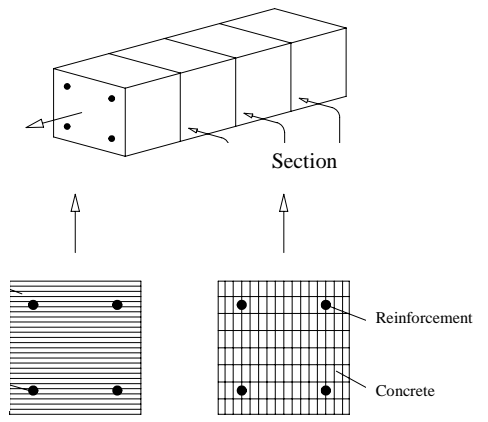

Figure 4: Fibre model for RC elements.

\subsection{Damage model}

Characterization and quantification of structural damage is essential for the structural response assessment of buildings under earthquake loading. The definition of a damage measure and corresponding quantification gives an important contribution for the objective interpretation of nonlinear analysis results. In practical terms, a damage measure indicates how close a specific structural member is from one limit-state. When subjected to earthquakes, reinforced concrete structures are generally damaged by a combination of repeated stress reversals and high stress excursions. Therefore, damage definition solely in terms of one factor is often inadequate. The so-called combined damage models are a class of damage model formulation very commonly used to assess structural behaviour under earthquake loading. Normally, this type of damage index combines two terms. The first term represents a measure of maximum structural deformation and the second represents a measure of the energy dissipated through hysteretic behaviour. One of the most widely used damage formulations is the Park and Ang [7]. This damage index is defined by a linear combination of the normalized maximum deformation and the normalized hysteretic energy resulting from cyclic loading. The damage index $\mathrm{D}$ is therefore defined by:

$$
D=\frac{\varphi_{\max }}{\varphi_{u}}+\beta \frac{\int d E}{M_{y} \cdot \varphi_{u}}
$$


where $\varphi_{\max }$ is the maximum curvature of the structural member, $\varphi_{u}$ is the ultimate curvature, $\int d E$ is the dissipated hysteretic energy, $M_{y}$ is the yielding moment and $\beta$ is a degradation parameter that represents the influence of the cyclic behaviour in the damage process and is function of structural parameters. A value of $D \geq 1$ represents total damage.

The presented damage index is usually calculated for the end zones of the structural members, where inelastic behaviour is expected under earthquake loads. It is commonly assumed that the global damage of a structure is result of the combination of local damage measures. Therefore, the global damage $D_{G}$ of a structure can be obtained by averaging the local damage indices weighed by the energy dissipated by hysteresis of each member:

$$
D_{G}=\frac{\sum_{i=1}^{n} D_{i} \cdot \int d E_{i}}{\sum_{i=1}^{n} \int d E_{i}}
$$

\subsection{Infill masonry model}

It is a common misconception that masonry infill in structural RC frames can only increase the overall lateral load capacity, and therefore, must always be beneficial to seismic performance. An hysteretic model for the simulation of the infill masonry panels based on the equivalent truss model, as presented in the Fig. 5, was implemented in the program PORANL by Rodrigues [10].

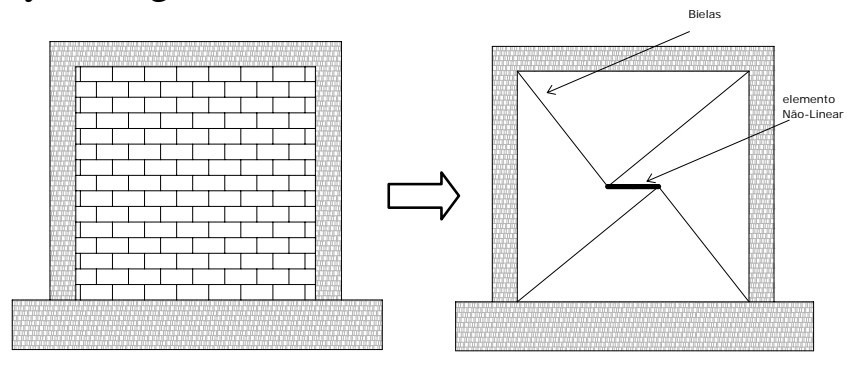

Figure 5: Proposed equivalent truss model.

In the model, each panel is represented by diagonal trusses with linear behaviour and a central element that simulates the non-linear behaviour of the infill panel. The non-linear behaviour of each panel, resumed in the central element, is represented by a hysteretic model, which contemplates important effects, such as: i) stiffness degradation; ii) strength degradation; iii) pinching and slipping effects. Panels are characterised by a multi-linear curve with five branches, as represented in Fig. 6, for each direction, allowing for the analysis of panels with non-symmetrical behaviour (for example: a panel with a non-centred opening).

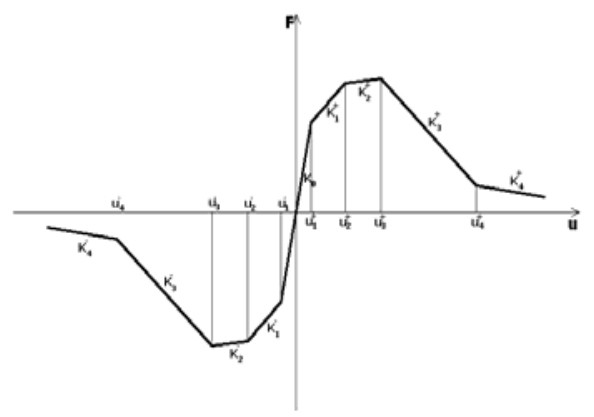

Figure 6: Envelop non-linear behaviour curve for the infill panel element. 


\section{PRE-PROCESSING}

\subsection{Introduction}

The graphical environment developed integrates the pre and powder-processing. In the next are described the basic steps of the data input interface, namely: geometry, loads definition, materials characteristics (with linear and non-linear behaviour) and supports.

Description of the pre-processor steps will be made in a logical sequence of a structural problem definition. However, as was referred before, it should be underlined that a great advantage of the developed interface relies in the possibility of data definition without obeying to a rigid sequence.

\subsection{Structure's geometry}

The structure's geometry can be generated in two different ways (see Fig. 7): i) defining an initial support mesh for the structure geometry, establishing the number of storeys and bays, with the respective dimensions; ii) importing a file in DXF format with the structural geometry. After the basic mesh of the structure, the user can: change the length of a bay or the height of a storey; add or delete frames; and, change node's coordinates.

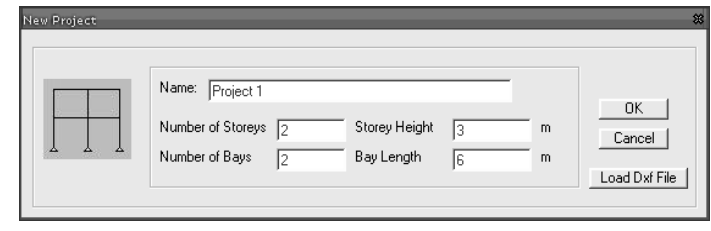

Figure 7: Structure geometry.

\subsection{Linear and non-linear sections}

Each frame element in the structure is modelled with three sub-elements, namely: a central element with linear behaviour and two sub-elements in the vicinity of the joints with nonlinear behaviour (see Fig. 1). To define the characteristics of the sub-elements with linear behaviour (see Fig. 8): width and height or moment of inertia and area of the cross-section; volumetric weight of the material and Young's modulus.

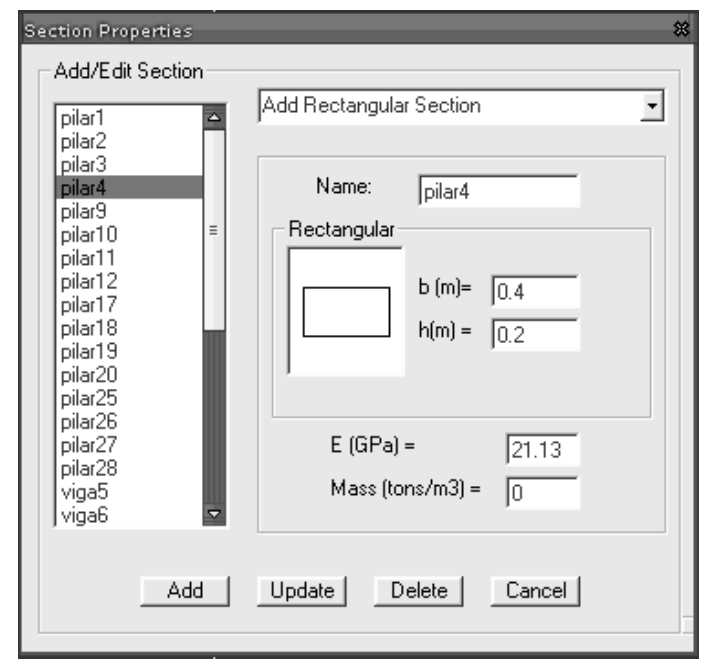

Figure 8: Elements with linear behaviour.

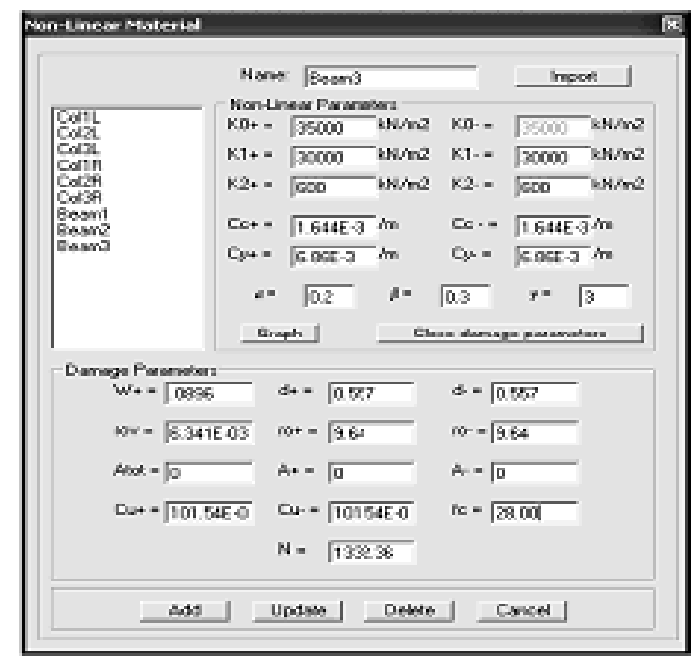

Figure 9: Non-linear behaviour definition of the sections. 
For each sub-element with non-linear behaviour, the so-called plastic hinges [1], the behaviour characteristics are defined (as shown in Fig. 9): parameters defining the tri-linear curve, as well as, the damage index parameters. The properties of the linear and non-linear sub-elements can be imported from a text file, introduced in the graphical tool, and modified or deleted, at any time.

\subsection{Frame properties}

For each frame or group of frames are assigned the following properties (figure 10): i) material with linear behaviour; ii) length of the plastic hinges; iii) material with non-linear behaviour associated to each plastic hinge.

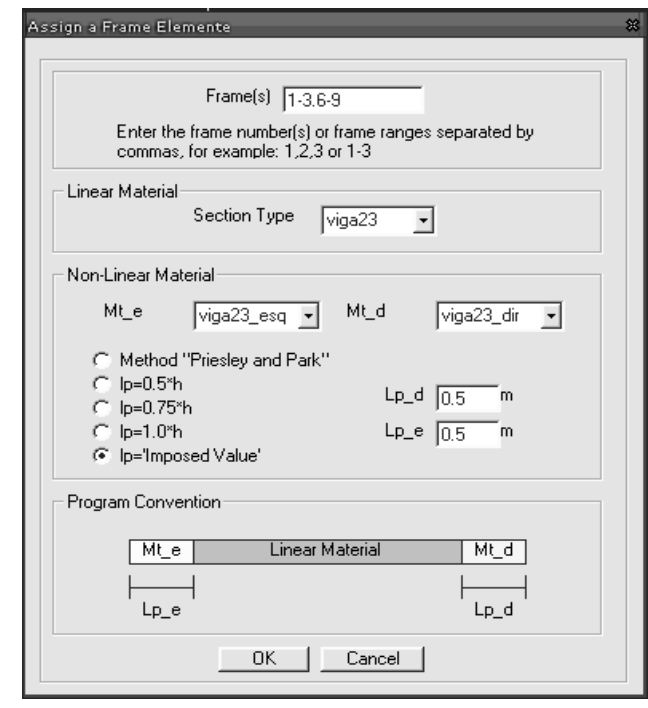

Figure 10: Frame element properties.

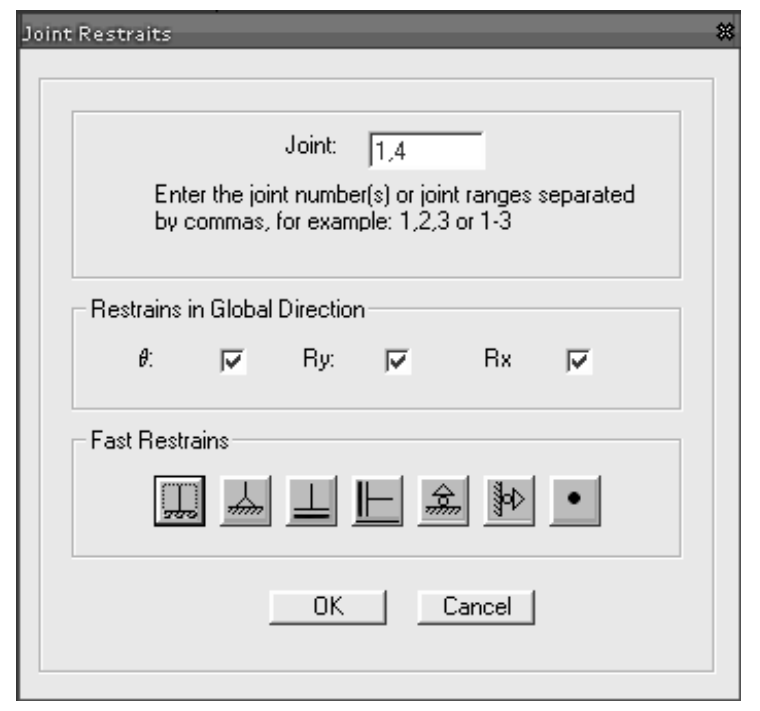

Figure 11: Support conditions.

\subsection{Nodal displacements restrictions (supports)}

The program formulation contemplates a 2D structural model. The user can restrict the degrees of freedom of a node, or a group of nodes, corresponding to the plane structural problem, namely, the displacement in the $\mathrm{x}$ or $\mathrm{y}$ direction or the rotation (Fig. 11). To facilitate the definition of support restrictions were defined shortcut keys for the possible support types.

\subsection{Infill panels}

To add an infill masonry panel to the frame structure, the user have to select the 4 nodes that confine the panel. This operation can be done in two different ways, namely: the user can write the node labels or select directly in the structure, with the mouse, the area where the infill panel must be considered (Fig. 12).

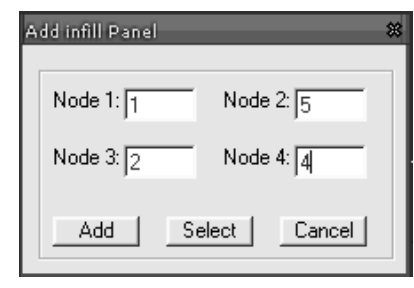

Figure 12: Infill panel definition. 
In the graphical environment VisualANL, it is represented the infill panels added to the structure (Fig. 13), and the user can define the masonry properties described previously.

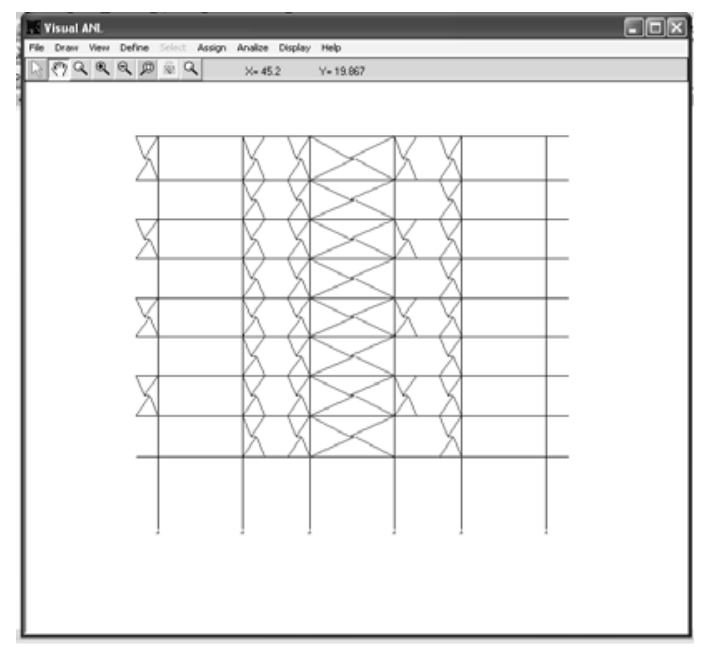

Figure 13: Infill panels geometry representation.

\subsection{Static loads}

The static loads considered in the PORANL are concentrated loads in nodes and uniformly distributed loads in frames. The concentrated static loads applied directly to the nodes, are forces in x or y direction or concentrated moments (see Fig. 14-a). For the distributed loads on frames, just the uniformly distributed load on the total frame length, and perpendicular to its axis, is implemented (as represented in the Fig. 14-b). Different load cases in the frames can be considered as equivalent concentrated nodal forces. In the dialogue windows for loads definition are represented the conventions adopted by the program PORANL.

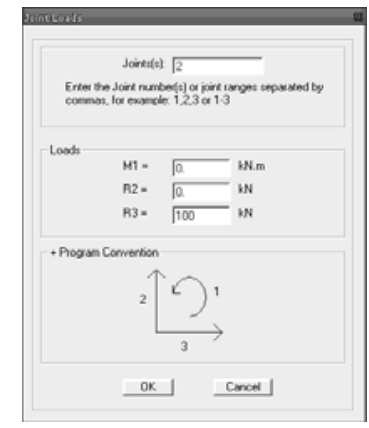

a) concentrated in nodes

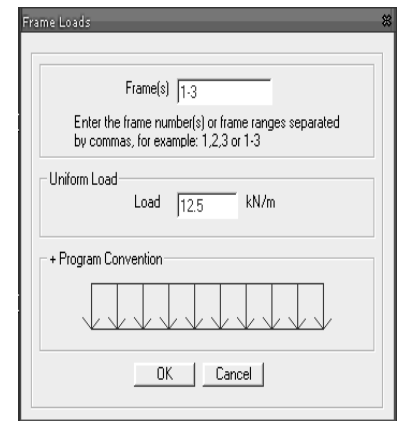

b) distributed in frames

Figure 14: Static loads.

\section{PROBLEM CALCULATION}

\subsection{Introduction}

In this paper it is presented essentially the graphical environment, VISUALANL, of support to the processor PORANL, a program of non-linear analysis of plane frames, developed by Varum [1]. VISUALANL generates the structural problem in a graphical environment, prepares a series of text files that constitutes the input data for the PORANL, executes the structural calculations with the PORANL, read the results from the PORANL, and using a series of post-processing options permits the graphical visualisation of the numerical results. 
In fact, two programs are used (VISUALANL and PORANL), although the user just works in the graphic environment VISUALANL without interacting directly with the nonlinear dynamic analysis program PORANL.

The program contemplates several analysis types, namely: i) static linear elastic analysis; ii) non-linear static analysis; iii) dynamic non-linear analysis; iv) non-linear analysis for imposed displacements; and, v) calculation of the natural frequencies and vibration modes of the structure. Each one of these options was implemented in VISUALANL.

\subsection{Static analysis}

Besides the data relative to the structure's geometry, material properties and loads, to execute a linear or non-linear static analysis, the user just have to choose the analysis type that intends to perform.

\subsection{Dynamic analysis}

To perform a dynamic analysis the user have to define: i) the accelerogram (imported from a text file); ii) the dynamic integration method to be used (Wilson- $\theta$, Newmark or Central Differences Method) [1, 2]; and, iii) the parameters for definition of the damping Rayleigh matrix [3], which can be calculated, in VISUALANL, as function of the assumed damping for two different natural frequencies. After importing the accelerogram to be used, it is represented (Fig. 15) and the user can apply a factor to increase or reduce the accelerogram, reduce to other integration time-step or cut part of the accelerogram. In the dialogue window of the accelerogram definition, Fig. 15, the user can define the time-steps for saving the structural response.

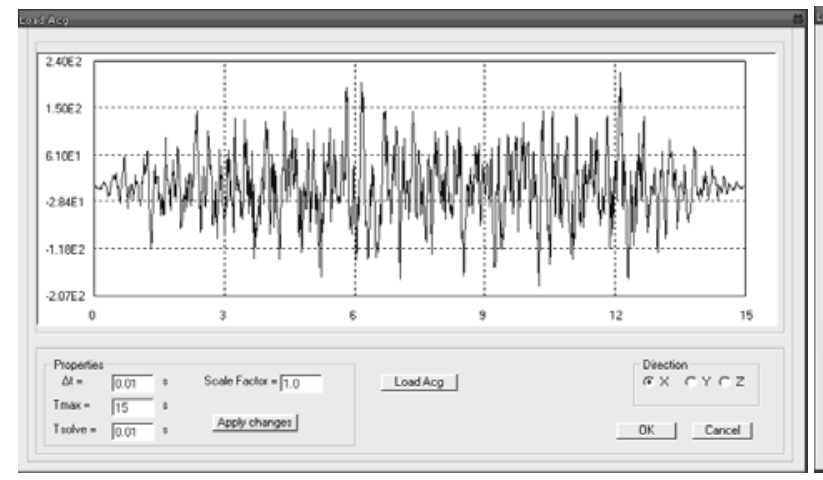

Figure 15: Accelerogram.

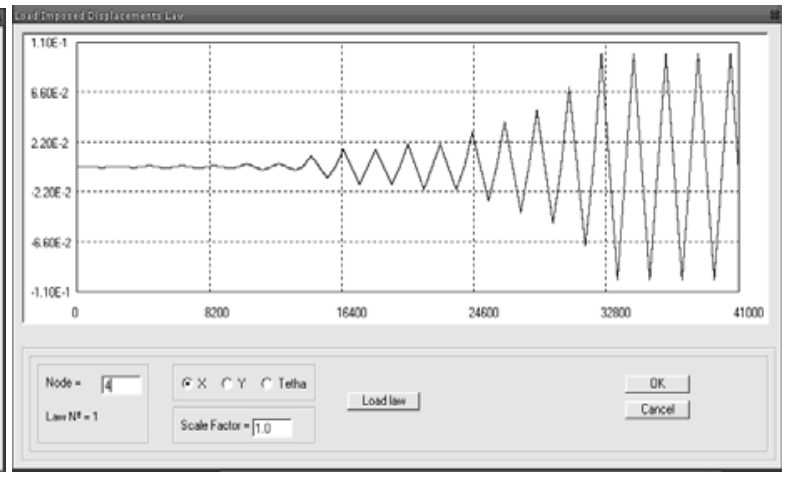

Figure 16: History of imposed displacement.

\subsection{Non-linear analysis with imposed displacements}

In the analysis with imposed displacements, it is imposed to one or more nodes a displacement law in a selected direction. The imposed displacement laws can be imported from text files, and it can be applied an increase/reduction factor to each individual law (see Fig. 16).

\subsection{Natural frequencies and vibration modes calculation}

In this option are calculated the natural frequencies of the structure and the corresponding vibration modes. The frequencies are presented in a table and the vibration modes represented graphically. With structural natural frequencies evaluated, they can be used for the calculation of the damping Rayleigh matrix coefficients. 


\section{POST-PROCESSING}

\subsection{Introduction}

The post-processing consists in the visualization of the structure calculation results and it implicates that all pre-processing instructions have been accomplished. The visualization options will depend on the type of analysis.

\subsection{Deformed shape}

With this option, Fig. 17, it is represented the original undeformed and the deformed shape of the structure, with a scale factor automatically calculated. However, the user can change it, in order to visualize the deformed structure in a more convenient scale.

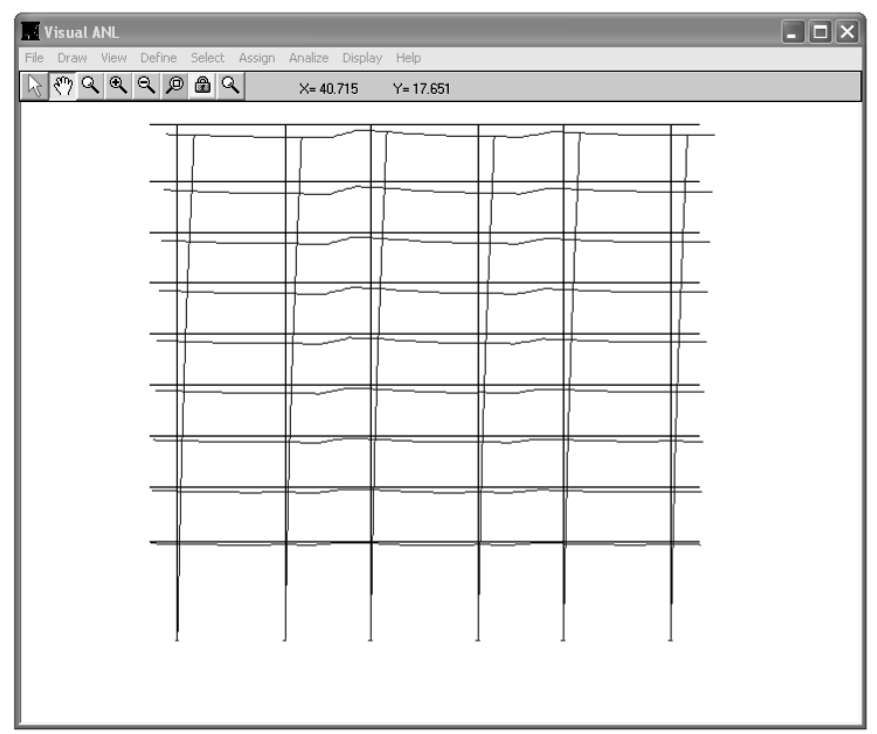

Figure 17: Deformed shape of the structure.

When the deformed shape is active, the user can select a frame with the mouse, visualizing: the deformed shape of that frame in the local referential axis; the positive and negative maximum values of the deformations; and, the value of the deformation at any point within the frame (Fig. 18).

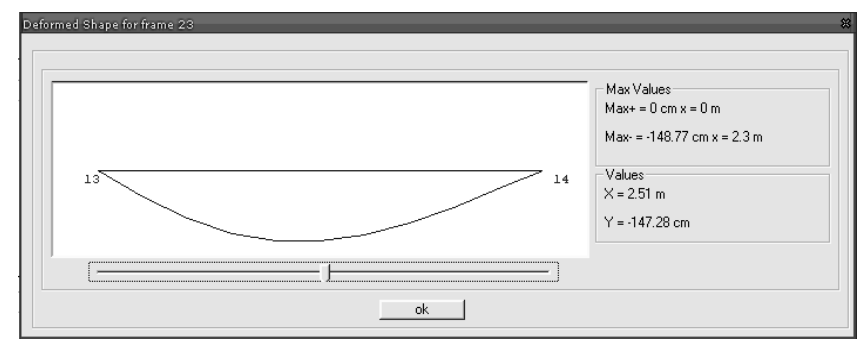

Figure 18: Deformed shape of an element.

\subsection{Diagrams}

The diagrams visualization follows similar procedure than the deformed shape. The user selects the time-instant in which pretends to represent the internal forces in the structure: axial force $N$, shear force $V$ or bending moment $M$ (see the example in Fig. 19). 


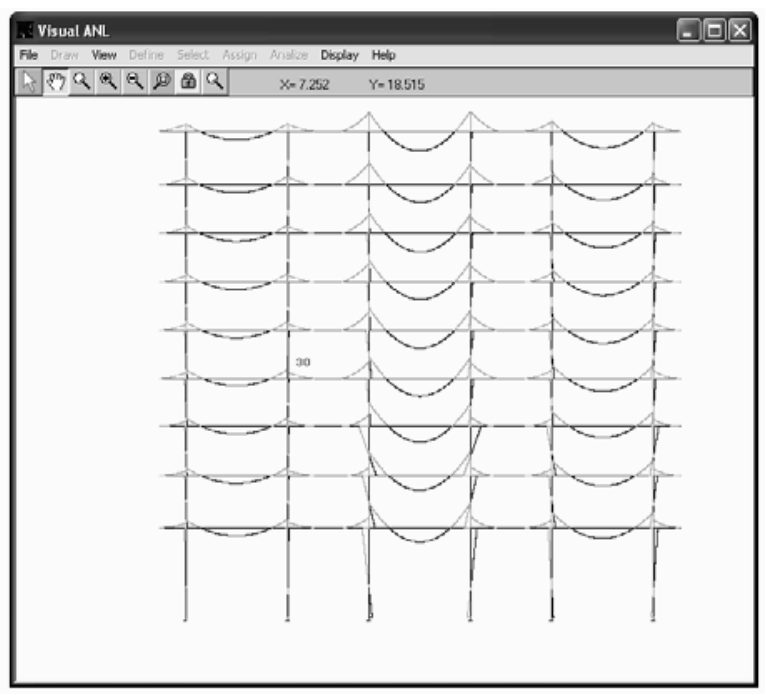

Figure 19: Bending moment's distribution in the structure.

When the diagrams are represented in the option window, it will appears the maximum positive and negative internal forces in the whole structure, been marked the element where they occurs (Fig. 20).

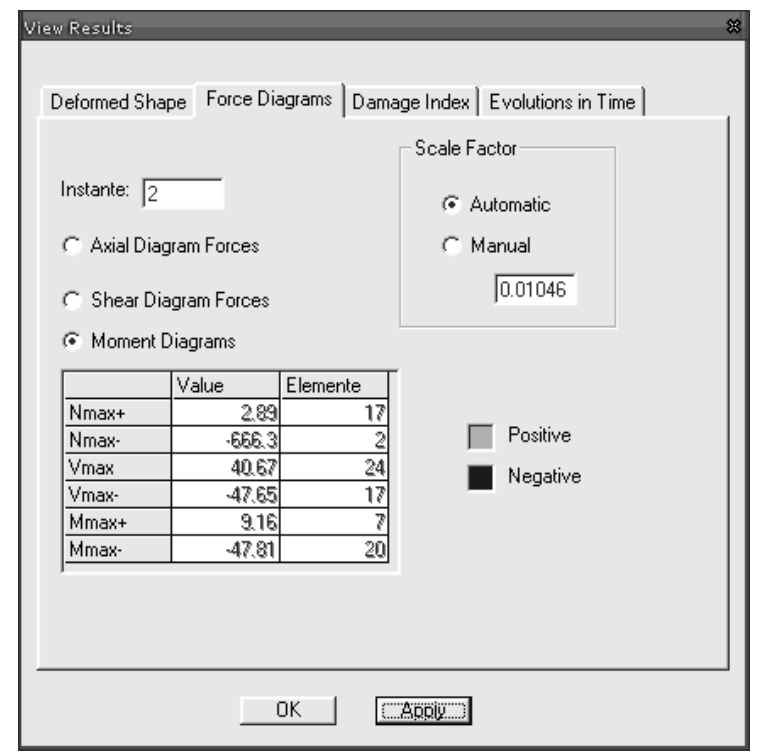

Figure 20: Window for diagram's options.

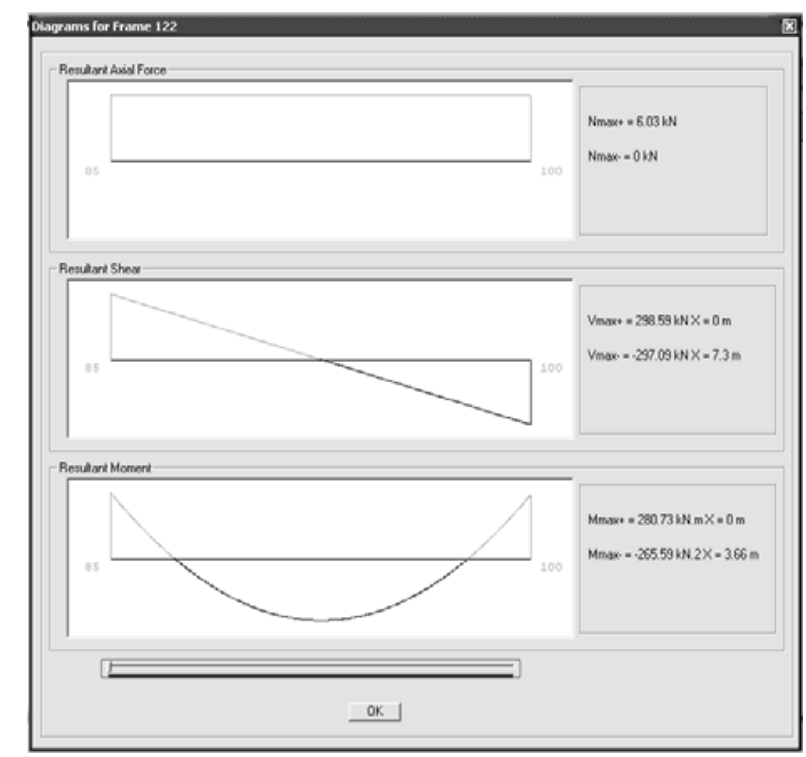

Figure 21: Diagrams for a single frame element $(\mathrm{N}, \mathrm{V}$ and $\mathrm{M})$.

The user can select a frame, visualizing their diagrams with indication of the maximum and minimum values, and it can be read the value at any point in the frame (Fig. 21).

\subsection{Damage index}

The formulation for the local and global damage index estimation was described previously. Regarding the damage index within the structure, three types of results can be visualized: the evolution of the global damage index for the whole structure; the maximum inter-storey drift profile, that represents the maximum relative displacement between consecutive floors, normalized by the height of this floor; and, a representation of the local damage index for each element for a certain time-step (Fig. 22). The program considers a pre-defined colours 
scale where each colour represents a damage level. However, the damage limits for each damage level, as well as the colour representing each damage level can be defined by the user.

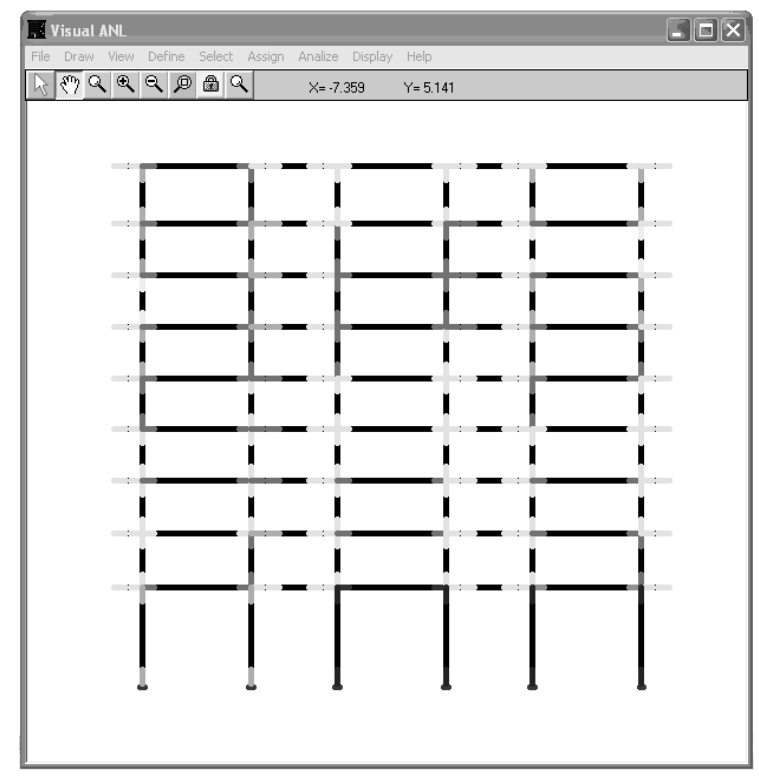

Figure 22: Damage index calculated within the structure.

\subsection{Evolutions}

In this option, the user can visualize: the time-evolution of internal forces ( $\mathrm{N}, \mathrm{V}$ and $\mathrm{M})$ or of the curvature in a plastic hinge; the graph moment-curvature at a plastic hinge (Fig. 23); and, the displacement evolution of a node in certain direction. Any graphic can be exported as a image format, or in a compatible MS Excel text files, and they can be visualized in detail with the same graphic tools developed for the general graphic atmosphere VISULANL (zoom, pan, etc.).

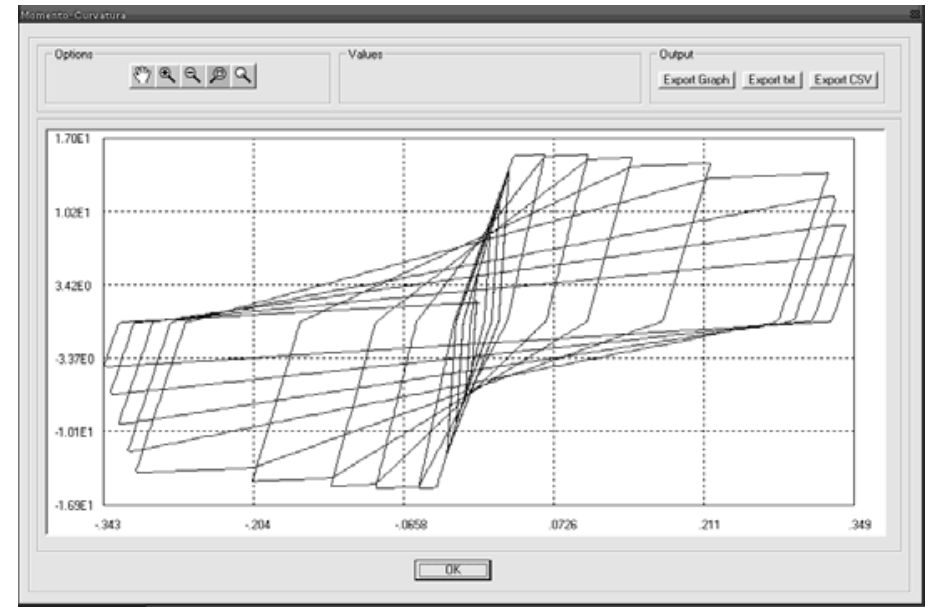

Figure 23: Moment-curvature diagram of a frame element.

\section{CONCLUSIONS}

The non-linear models are a valuable tool in the analysis and verification of the structural safety. They give to the engineer capacity to represent more precisely the real behaviour of the structures. For the design of new structures or for the capacity assessment of existent 
structures, the non-linear analyses make possible a better representation of the structural response, for any load action, and to earthquakes, in particular. Furthermore, non-linear models can be used in the calibration of more simplified models.

Recent standards suggest the non-linear analyses as the reference analyses to be used in the capacity evaluation and verification of structural safety. Eurocode 8 [9] recommends the use of non-linear analysis methods with time-integration for assessment of existent RC structures.

The non-linear analyses with step-to-step integration generates an enormous amount of information (nodal displacements, internal forces in frame elements, deformations, etc.), for each time-instant of the analysis, making its treatment and interpretation difficult.

Although the high number and development of the non-linear models, just a few nonlinear programs have graphical tools for results visualization. Therefore, it is considered that the developed graphic processor will be a helpful tool for the non-linear analysis in support to the design of new structures and, especially, in the capacity assessment of existing ones, for severe static and/or dynamic loads.

\section{REFERENCES}

[1] Varum, H. (1996). Modelo numérico para a análise sísmica de pórticos planos de betão armado, MSc Thesis, FEUP

[2] Clough, R. W.; Penzien, J. (1993). Dynamics of structures, Second Edition, McGraw-Hill International Editions

[3] Alconchel, J. D. (1999). Superutilidades para Visual Basic, McGraw-Hill

[4] Romão, X. (2002). Novos modelos de dimensionamento sísmico de estruturas, MSc Thesis, FEUP

[5] Costa, A. G. (1989). Análise sísmica de estruturas irregulares, PhD Thesis, FEUP

[6] Vaz, C. T. (1996). Análise não-linear de pilares de betão armado sob cargas cíclicas, LNEC, Lisbon

[7] Park, Y. J.; Ang, H. S. (1985). Mechanistic seismic damage model for reinforced concrete, Journal of Structural Engineering ASCE, Vol. 111, No. 4, 722-739

[8] Varum, H.; Costa, A. G. (1997). Modelo não-linear para a análise estática e/ou dinâmica de pórticos de betão armado, $3^{\circ}$ Encontro de Sismologia e Engenharia Sísmica, Instituto Superior Técnico, Lisboa

[9] CEN (2003) - EUROCODE 8: Design of structures for earthquake resistance - Part 1-3: Strengthening and repair of buildings - European prEN 1998-1-3, European Committee for Standardization, Brussels, Belgium

[10] Rodrigues, H.; Varum, H.; Costa, A. G.; Romão, X. (2004). Interface gráfico para análise nãolinear de pórticos planos sujeitos a cargas dinâmicas e/ou estáticas, Congresso de Métodos Computacionais em Engenharia - CMCE 2004, LNEC, Lisboa

[11] Takeda, T.; Sozen, M. A.; Nielsen, N. N. (1970), Reinforced concrete response to simulated earthquakes, Journal Structural Division, ASCE, Vol. 36, No. ST12

[12] Costa, A. G.; Costa, A. C. (1987). Modelo Histerético das Forças-Deslocamentos Adequado à Análise Sísmica de Estruturas, Relatório Técnico, Núcleo de Dinâmica Aplicada, Laboratório Nacional de Engenharia Civil, Lisboa

[13] Williams, M. S.; Sexsmith, R. G. (1995). Seismic Damage Indices for Concrete Structure: A State-of-the-art Review, Earthquake Spectra, Vol. 11, No. 2, 319-349

[14] Rodrigues, H.; Varum, H.; Costa, A. G. (2005). Modelo Numérico não-linear para painéis de Alvenaria de Enchimento em Pórticos de Betão Armado, Congreso Métodos Numéricos en Ingeniería, E.T.S. de Ingenieros de Caminos de la Universidad de Granada 